\title{
STRATEGI MANAJEMEN PERUBAHAN UNTUK MENDUKUNG IMPLEMENTASI SISTEM INFORMASI RUMAH SAKIT STUDI KASUS: RSUD RAA SOEWONDO PATI
}

\author{
Achmad Nizar Hidayanto, Dian Setia Hartana, dan Ika Chandra Hapsari \\ Fakultas Ilmu Komputer, Universitas Indonesia, Kampus Baru UI Depok, Jawa Barat, 16424, Indonesia \\ E-mail: nizar@cs.ui.ac.id
}

\begin{abstract}
Abstrak
Seiring dengan perkembangan rumah sakit dan teknologi informasi, Sistem Informasi Rumah Sakit (SIRS) RAA Soewondo dirasa tidak mampu lagi memenuhi kebutuhan informasi. Keterbatasan tersebut membuat pihak manajemen berencana mengganti SIRS mereka. Agar implementasi SIRS yang baru dapat berhasil, perlu dilakukan strategi manajemen perubahan yang tepat pada rumah sakit. Penelitian ini bertujuan untuk merumuskan strategi manajemen perubahan untuk implementasi SIRS di RAA Soewondo. Penelitian dilakukan menggunakan pengambilan data melalui kuesioner, wawancara, dan observasi. Tindakan perubahan didapat dengan analisis SWOT, kemudian dikelompokan ke dalam metode manajemen untuk membuat strategi manajemen perubahan. Metode manajemen perubahan yang digunakan adalah Anderson dan Anderson Nine Phase Model. Dari hasil penelitian, didapatkan hasil bahwa faktor resistensi karyawan relatif kecil. Tindakan perubahan yang sesuai dengan manajemen perubahan adalah dukungan pimpinan untuk implementasi perubahan SIRS, membuat persamaan visi dan misi ke semua bagian rumah sakit tentang perubahan SIRS, merancang keadaan perubahan yang diinginkan dengan memerhatikan divisi yang terpengaruh oleh perubahan SIRS ini, melakukan penggantian dengan metode pararel cutover, memberikan penghargaan kepada karyawan yang ikut menyukseskan program ini, serta membuat kebijakan baru agar kebijakan yang sudah berjalan menjadi permanen. Hasil akhir menunjukkan secara umum karyawan rumah sakit setuju akan perubahan SIRS saat ini.
\end{abstract}

Kata Kunci: manajemen perubahan, sistem informasi rumah sakit, strategi perubahan

\begin{abstract}
Along with the development of hospitals and information technology, the Soewondo RAA Hospital Information System (SIRS) felt unable to meet the information needs. These limitations make the management of SIRS plans to replace their SIRS. In order for successful implementation of new SIRS, change management strategy needs to be done right at the hospital. This study aims to formulate strategies for implementing change management in the RAA Soewondo SIRS. The study was conducted using data collection through questionnaires, interviews, and observation. Action changes obtained with SWOT analysis and then grouped into a management method for making the change management strategy. Change management method that had been used is Anderson and Anderson Nine Phase Model. The study shows that the staff's resistance is relatively small. Action changes according that related to change management is leadership support for implementation of changes to SIRS, making equality vision and mission to all parts of the hospital about the change of SIRS, designing state of the desired changes with respect to the division that is affected by changes in SIRS, do the replacement with parallel cutover method, presents awards to employees who make this program succeed, and create new policies to estabilish policies that are already running to be permanent. The final results shows: in general, the employees agreed to change the current SIRS.
\end{abstract}

Keywords: change management, hospital information systems, strategy changes

\section{Pendahuluan}

Rumah sakit RAA Soewondo sebagai rumah sakit umum daerah Pati memiliki visi menjadi pusat pelayanan kesehatan terbaik di wilayah Karasidenan Pati dan juga menjadi tumpuan dan kebanggaan masyarakat serta karyawan tahun 2015. Misinya adalah memberikan pelayanan kesehatan bermutu, profesional, terjangkau, serta dijiwai moral dan etika demi kepuasan masyarakat. Untuk mencapai visi dan misi ini, RAA Soewondo tidak dapat lepas dari peranan teknologi informasi (TI).

Sistem Informasi Rumah Sakit (SIRS) RAA Soewondo yang ada saat ini kurang mampu memenuhi kebutuhan informasi untuk mendukung proses bisnis. SIRS saat ini menggunakan Windows DOS Foxpro 2.0 yang bersifat client- 
server melalui jaringan Local Area Network (LAN) rumah sakit. Biaya perawatan SIRS menjadi mahal karena telah menjadi sistem yang unik dan legacy pada saat ini. Oleh karena itu, perbaikan dan pengembangan SIRS perlu dilakukan.

Pihak rumah sakit akan mengganti SIRS yang lama dengan yang baru. Pihak rumah sakit berencana melakukan migrasi SIRS ke dalam bentuk desktop based client-server sehingga mudah dioperasikan dalam lingkungan internal rumah sakit. Agar proses implementasi berjalan lancar dan sesuai dengan jadwal yang ditetapkan maka perlu dilakukan manajemen perubahan proyek TI yang tepat. Hal ini karena salah satu alasan utama penyebab kegagalan dalam pengimplementasian proyek adalah kurangnya implementasi proses manajemen perubahan, tidak hanya di bagian TI tetapi di seluruh organisasi [1].

Penelitian ini bertujuan untuk mengetahui tingkat resistensi karyawan terhadap sistem informasi yang baru. Selain itu, penelitian ini bertujuan untuk mencari strategi manajemen perubahan yang cocok diterapkan pada SIRS RAA Soewondo Pati. Analisis yang digunakan dalam penelitian ini adalah analisis kuantitatif dan kualitatif, dengan memperhatikan keadaan internal dan eksternal rumah sakit.

Penelitian terkait, beberapa penelitian yang terkait dengan topik ini telah dilakukan sebelumnya. Penelitian yang dilakukan oleh Jack dan Peiper [2] menyebutkan bahwa inisiatif terhadap perubahan perlu dilakukan oleh manajer proyek agar proyek dapat berjalan dengan sukses. Penelitian yang dilakukan oleh Levinson [1] menghasilkan kesimpulan bahwa salah satu penyebab kegagalan dari suatu proyek adalah kurangnya implementasi dari proses manajemen perubahan, tidak hanya di bagian TI, tetapi juga dalam organisasi secara keseluruhan. Metode yang digunakan dalam penelitian ini adalah metode yang sebelumnya telah digunakan oleh Mutholib, E.A [3]. Persamaan dari ketiga penelitian tersebut adalah penggunaan strategi manajemen perubahaan untuk mendukung implementasi sistem yang baru.

Analisis SWOT, Strengh, Weakness, Opportunity, dan Threat (SWOT) diperlukan dalam menganalisis keadaan rumah sakit saat ini. Strength dan Weakness merupakan faktor-faktor internal dalam organisasi. Sedangkan Opportunity dan Threat merupakan faktor yang berasal dari luar organisasi. Hasil SWOT yang didapat akan digunakan untuk merumuskan strategi organisasi secara sistematis [4]. Dalam kasus ini, hasil dari analisis SWOT akan digunakan sebagai strategi perubahan dalam implementasi SIRS baru.
Faktor Penyebab Resistensi terhadap Perubahan, resistensi muncul pada saat perubahan yang terjadi. Resistensi dapat jelas terlihat (eksplisit) ataupun tersirat (implisit). Faktor penyebab penolakan dapat dibedakan menjadi dua yaitu penolakan individu dan penolakan organisasi [5]. Faktor penyebab resistensi individu yaitu: rasa aman, faktor ekonomi, persepsi, ketidakpastian, dan kebiasaan. Sedangkan faktor penyebab resistensi organisasi ada enam yaitu: dampak luas perubahan, inersia kelompok, ancaman alokasi sumber daya, ancaman kekuasaan, ancaman keahlian, dan inersia struktural.

Manajemen perubahan adalah aplikasi pengetahuan, kemampuan, alat, dan teknik untuk menggabungkan perubahan menjadi sebuah proyek dan atau menjadi sebuah strategi [6]. Strategi perubahan meliputi 3 hal yaitu: (1) Content yaitu area di dalam organisasi dan teknis yang harus berubah. (2) People yaitu perubahan pola pikir, tingkah laku, dan budaya yang harus diperlukan dalam perubahan [7]. (3) Process yaitu tindakan yang harus dilakukan untuk merencanakan, membentuk, dan mengimplementasikan semua perubahan secara terintegrasi dan menyeluruh.

Metode Penggantian Sistem Informasi., terdapat tiga metode dalam penggantian SI dalam organisasi [8]. Pertama, Metode Immediate Cutover. Metode ini memiliki tingkat risiko kegagalan implementasi yang tinggi namun cepat dalam hal menggantikan sistem informasi lama. Investasi TI yang dibutuhkan kecil. Kedua, Metode Pararel Cutover. Metode ini memiliki tingkat risiko kegagalan implementasi yang rendah. Pada implementasi nanti terdapat dua sistem (lama dan baru) yang berjalan pada saat yang bersamaan. Pemutusan sistem informasi lama dilakukan bila pengguna sudah siap dan terbiasa dengan sistem yang baru. Metode ini memiliki investasi TI yang tinggi untuk menyediakan 2 sistem berjalan. Ketiga, Metode Phased Cutover. Metode ini adalah penggabungan dari dua metode sebelumnya. Penggantian sistem lama dilakukan per fase. Misalnya terlebih dahulu dilakukan oleh 1 unit bisnis d kemudian baru unit bisnis yang lain, atau dilakukan per aplikasi.

Anderson dan Anderson Nine Phase Change Process Model. Model ini berisi sembilan fase perubahan. Setiap fase terdiri dari beberapa aktivitas dan tugas yang dapat diikuti untuk merencanakan, mendesain, dan mengimplementasi perubahan.

Prepare to lead the change. Dalam fase ini, ditentukan key people leader. Key people leader bertujuan untuk menyiapkan pemimpin yang akan mengendalikan perubahan. Create Organizational 
Vision, Commitment, and Capacity. Fase ini bertujuan menbangun pengertian, komitmen, momentum dan kapasitas perubahan, khususnya di antara para stakeholder, dan pada seluruh elemen organisasi umumnya. Assess the Situation to Determine Design Requirements. Fase ini bertujuan melihat keadaan dan situasi yang ada pada organisasi untuk membuat rancangan perubahan yang realistis. Design the Desired State. Fase ini membantu organisasi merancang keadaan perubahan yang diinginkan. Analyze the Impact. Fase ini menganalisis pengaruh perubahan didalam organisasi, orang, dan kebiasaannya sebagai dasar untuk merencanakan proses implementasi yang realistis. Plan and Organize for Implementation. Fase ini mengidentifikasi langkah apa yang diperlukan untuk menuju ke arah keadaan yang diinginkan. Implement the Change. Fase ini mengimplementasikan perubahan di dalam organisasi. Celebrate and Integrate the New State. Pada fase ini dirayakan kemenangan atas hasil perubahan yang didapat dan memberi tahu organisasi bahwa mereka sudah masuk dalam keadaan yang baru. Learn and Course Correct. Fase ini menciptakan mekanisme untuk terus memerbaiki keadaan yang sudah berubah dan menjadikannya permanen.

\section{Metodologi}

Penelitian ini menggunakan metodologi penelitian studi kasus pada organisasi yang bergerak di bidang layanan kesehatan. Metode penelitian yang digunakan adalah metode penelitian kuantitatif dan kualitatif. Metodologi penelitian ini mengikuti metode penelitian Mutholib yang juga dilakukan di rumah sakit dengan sedikit perubahan yang disesuaikan [3].

Metode Pengumpulan Data, ada dua jenis data yang dikumpulkan pada penelitian ini, data primer dan data sekunder. Data primer adalah data yang diambil langsung dari rumah sakit RAA Soewondo. Sedangkan data sekunder merupakan data yang diperoleh dari pihak kedua.

Data primer didapatkan dengan tiga cara, yaitu wawancara, observasi, dan kuesioner. Wawancara dilakukan pada direktur dan beberapa pejabat rumah sakit yang berhubungan dengan SIRS. Wawancara dilakukan untuk mengetahui lebih mendalam permasalahan yang ada pada proses rencana implementasi SIRS baru. Observasi dilakukan untuk mengetahui keadaan lingkungan rumah sakit dalam kegiatannya seharihari. Cara ini lebih digunakan untuk mengetahui keadaan langsung di lapangan terhadap proses implementasi SIRS baru. Kuesioner diberikan kepada karyawan rumah sakit khususnya di bagian-bagian yang memiliki aliran dana dan aliran informasi. Terdapat tiga kategori pertanyaan dalam kuesioner ini, yaitu: kategori wawasan tentang pengorganisasian rumah sakit, kategori tugas, dan fungsi teknologi informasi, serta kategori kemampuan komputer responden.

Sedangkan data sekunder didapat dengan cara mengambil dari pihak kedua seperti dokumentasi yang sesuai dengan penelitian di rumah sakit. Data sekunder juga diambil dari buku referensi dan jurnal yang berkaitan dengan tujuan penelitian.

Tahap proses penelitian di rumah sakit RAA Soewondo terdari dari enam tahapan. Pertama, mengidentifikasi masalah sebagai dasar penelitian. Kedua, melakukan studi pustaka untuk mendapatkan informasi dan data yang diperlukan untuk membuat persiapan penelitian. Ketiga, pengumpulan data, baik data primer maupun sekunder. Keempat, melakukan analisis resistensi perubahan. Analisis ini akan menghasilkan output berupa faktor-faktor yang menyebabkan terjadinya penolakan terhadap SIRS. Kelima, analisis SWOT dilakukan untuk menghasilkan tindakan perubahan yang sesuai dengan kondisi rumah sakit saat ini. Keenam, mengelompokkan langkah-langkah perubahan ke dalam metode manajemen perubahan Anderson dan Anderson. Pengelompokan ini bertujuan untuk mengklasifikasikan tindakan perubahan menjadi strategi manajemen perubahan.

\section{Analisis dan Pembahasan}

Kondisi teknologi informasi saat ini, SIRS di RSUD RAA Soewondo berusia kurang lebih lima tahun dengan menggunakan bahasa pemrograman FoxPro 2.0 LAN Network Novel. SIRS ini berjalan dalam lingkungan Disk Operating System (DOS). Database yang digunakan untuk mencatat data transaksi dan data pasien menggunakan internal database dari Foxpro (dbf dan fxp file). Database sampai saat ini berukuran 1-2Gb. Penulisan data pasien di dalam database menggunakan nomor registrasi pasien yang bersifat unik (misalnya: 01896209, 2 digit terakhir menunjukkan tahun). Nomor registrasi ini dapat digunakan untuk mengakses database yang berbeda.

SIRS berjalan dengan sistem server-client. Sistem client tidak memiliki harddisk dan harus boot dengan Floppy Drive disket untuk dapat terkoneksi ke sistem server. Server utama dan backup server ditempatkan pada sebuah ruang kecil ber-air conditioner. Ruangan ini juga digunakan sebagai kantor bagian SIM yang terdiri dari enam orang. Ruang kantor ini juga dijadikan tempat penyimpanan alat-alat komponen 
komputer seperti monitor, PC, atau printer yang ditempatkan sebagai cadangan ataupun sedang dalam perbaikan. Server utama berupa PC rakitan dengan spesifikasi Processor ( Pentium 42.6 Ghz), Memory $1 \mathrm{~Gb}$, Hard disk $40 \quad$ Gb, Gigabit LAN, dan DVDRW optical drive.

Sistem SIRS saat ini adalah gabungan dari beberapa sistem informasi dari tiap bagian dan terpusat ke satu server dan database. SIRS menggunakan LAN untuk koneksi ke client tanpa memiliki hubungan ke luar (Internet). Sistem informasi tersebut antara lain: (1) Sistem informasi Pembayaran, (2) Sistem informasi Pendaftaran, (3) Sistem informasi Logistik, (4) Sistem informasi Farmasi, (5) Sistem informasi Rawat Jalan,(6) Sistem informasi Rawat Inap, (7) Sistem informasi Keperawatan, (8) Sistem informasi Rekam Medis.

Selain sistem informasi yang terintegrasi dalam satu SIRS ini, rumah sakit RAA Soewondo juga memiliki beberapa sistem informasi lain, yang terpisah dari SIRS. Sistem informasi yang dimaksud adalah sistem kepegawaian (SIMDA) yang terhubung ke Pemda Pati, Sistem Mobilisasi Dana yang terhubung dengan Bank Daerah Jawa Tengah, sistem ASKES yang terhubung dengan Askes Persero, serta Sistem Jaminan Kesehatan Masyarakat Miskin (Jamkeskin) yang terhubung dengan Departemen Kesehatan RI (DEPKES).

Kekurangan dan kelebihan SIRS saat ini, terdapat lima kekurangan yang ada pada sistem saat ini.Pertama, Shared database violation, yaitu keterbatasan fitur pada database internal Foxpro tidak memungkinkan record data yang sama dimodifikasi pada saat yang bersamaan. Kedua, SIRS yang dibuat dalam bahasa pemrograman Foxpro tidak dapat dijalankan pada processor di atas Pentium 4. Ketiga, PC Client harus boot dengan floppy disket untuk dapat koneksi dengan SIRS. Ketersediaan disket saat ini sudah menjadi barang langka dan jarang ditemui di pasaran. Keempat, menu pada SIRS sangat banyak dan untuk kembali menuju menu awal harus melewati beberapa menu didepannya. Proses ini sangat lama dan memakan waktu dibandingkan dengan model menu drop-down pada aplikasi desktop base. Terakhir adalah aplikasi. Foxpro 2.0 tidak didukung lagi oleh Microsoft. Aplikasi ini dirilis terakhir pada versi 2.6 dan berganti nama dengan Visual Foxpro. Microsoft sendiri sudah tidak lagi menjual Visual Foxpro dan hanya support sampai tahun 2015.

Sedangkan kelebihan SIRS Foxpro ini adalah ukuran programnya yang kecil, client diskless dan membutuhkan sumber daya komputer yang rendah seperti processor dan memory yang kecil. Kemudian server utama memiliki satu buah backup server yang berfungsi untuk menggantikan server utama bila terjadi kerusakan sehingga SIRS tidak terganggu dan proses sistem informasi tetap berjalan. SIRS juga terhubung ke client melalui kabel jaringan lokal ke hampir seluruh bagian rumah sakit, terutama bagian yang memiliki aliran informasi dan aliran dana.

Perbaikan Teknologi Informasi, sistem informasi rumah sakit yang sekarang berjalan akan diganti dengan sistem yang baru. Proses remunerasi pegawai yang transparan dan akurat menjadi perhatian utama perbaikan. Saat ini sistem remunerasi masih menggunakan acuan tingkat jabatan dan lama bekerja di rumah sakit. Sistem informasi yang baru menggunakan acuan berbeda yaitu unit cost, investasi unit dan jasa pelayanan. $50 \%$ hasil pendapatan dari transaksi pelayanan kesehatan akan diberikan kepada individu yang memberikan layanan kesehatan, $50 \%$ sisanya dimasukkan kedalam dana pos remunerisasi. Dana pos remunerisasi akan dibagikan kepada seluruh karyawan rumah sakit berdasarkan poin masing-masing karyawan. Poin ini dibedakan atas jabatan, lama bekerja, dan risiko pekerjaan seseorang di rumah sakit. Telah disepakati SIRS baru akan menggunakan aplikasi yang berjalan di dekstop, bukan DOS seperti saat ini.

Hasil Kuesioner, total responden kuesioner ini adalah 78 orang yang terbagi dalam 2 bagian utama yaitu 34 responden (44\%) di Bagian Administrasi dan Keuangan, 44 responden (56\%) di Bagian Pelayanan. Bagian Administrasi dan Keuangan meliputi sub bagian Program dan SIM, Keuangan, dan Tata Usaha. Bagian Pelayanan meliputi Seksi Pelayanan, Keperawatan, dan Penunjang (laboratorium, farmasi). Responden kuesioner sebagian besar adalah staff bagian, Apoteker, Pelayanan Informasi, dan kepegawaian. Terdapat dua responden yang menjabat sebagai dua Kepala Bagian dan tiga Kepala Instansi.

Posisi RSUD RAA Soewondo Dibanding Rumah Sakit Lain, sebanyak $67 \%$ responden menjawab RAA Soewondo menempati posisi terdepan, 24\% responden menjawab RAA Soewondo memiliki posisi yang sama dengan rumah sakit lain, dan $4 \%$ menjawab tidak tahu.

Keberhasilan Sosialisasi di RS RAA Soewondo, sebanyak $90 \%$ responden menyatakan bahwa kegiatan sosialisasi di rumah sakit berjalan lancar, 8\% mengatakan tidak ada sosialisasi di rumah sakit, dan sisanya menjawab tidak tahu.

Peranan Atasan dalam Penyampaian Informasi, sebanyak $90 \%$ responden mengatakan keberhasilan kegiatan tergantung pada dukungan seluruh tingkatan organisasi. Hanya $6 \%$ yang mengatakan bahwa keberhasilan kegiatan rumah sakit dilakukan oleh dukungan operasional (Kepala Bagian dan Staff) dan sisanya menjawab 
penyampaian informasi dilakukan oleh dukungan eksekutif (Direktur dan Asisten Direktur).

Cara penyampaian informasi kegiatan yang paling efektif menurut hasil kuesioner, $46 \%$ responden menjawab melalui pertemuan berkala, $18 \%$ menjawab melalui rekan kerja, $17 \%$ menjawab dalam setiap kesempatan, $15 \%$ responden menjawab penyampaian paling efektif melalui surat atau memo dan sisanya menjawab lain-lain (saat apel pagi kantor dan papan pengumuman).

Kemudahan Operasional SIRS, sebanyak $80 \%$ responden mengatakan bahwa SIRS yang ada saat ini mudah dioperasikan. Sedangkan $16 \%$ responden mengatakan operasional SIRS agak susah, dan sisanya mengatakan susah.

Penggantian SIRS Baru, sebanyak 74\% (55 responden) setuju dengan adanya penggantian SIRS lama. 55 responden ini meliputi 25 responden dari bagian Administrasi dan Keuangan dan 30 responden bagian Pelayanan. Hanya 16\% responden (12 orang) yang mengatakan tidak setuju meliputi 7 responden dari bagian Administrasi dan Keuangan dan 5 responden bagian Pelayanan. 2 responden (3\%) mengatakan lain-lain (tergantung atasan), 9 responden (7\%) tidak mengisi data isian kuesioner.

Terdapat beberapa masukan yang diberikan oleh responden yang menjawab setuju. (a) Setuju SIRS diganti bila langkah pengoperasiannya lebih mudah dari SIRS sebelumnya. (b) Data yang dihasilkan lebih cepat dan akurat. (c) Setuju bila ditambah program baru namun program lama tidak harus diganti. (d) Penggantian SIRS sesuai dengan perkembangan era komputerisasi.

Selain itu terdapat dua alasan responden tidak setuju dengan perubahan SIRS. (a) SIRS yang sekarang sudah cukup memadai sehingga tidak perlu diganti. (b) SIRS lama hanya perlu disempurnakan saja tanpa harus diganti.

Peranan SIRS dalam Mencapai Visi, Misi dan Tujuan. Dari 78 responden ini, 72 responden (93\%) mengatakan bahwa SIRS sangat membantu mencapai visi, misi, dan tujuan rumah sakit RAA Soewondo. 4 responden (5\%) mengatakan sedikit membantu, 1 responden tidak tahu, dan 1 responden tidak mengisi form. 72 responden $(92 \%)$ dari 78 total responden menggunakan komputer dalam pekerjaannya sehari-hari, hanya 6 responden yang tidak menggunakan komputer. Kemudian sebanyak 68 responden, (94\%) mengatakan bahwa SIRS dapat mempercepat pekerjaanya dan hanya 4 responden yang menjawab tidak mempercepat pekerjaan seharihari.

Dapat disimpulkan bahwa SIRS membantu visi, misi dan tujuan rumah sakit RAA Soewondo.
SIRS juga mampu membantu karyawannya dalam memercepat pekerjaan mereka sehari-hari.

Hasil Wawancara. Wawancara dilakukan kepada beberapa pejabat di lingkungan rumah sakit RAA Soewondo untuk mendapatkan informasi dari sudut pandang mereka. Informasi didapatkan dari hasil wawancara mengenai apa saja yang telah mereka lakukan atau apa yang akan mereka lakukan untuk implementasi SIRS baru nanti. Hasil wawancara tersebut terdiri dari 11 poin. (1) Adanya keluhan dari bagian Keperawatan, Farmasi, dan Rekam Medis tentang SIRS yang ada sekarang karena kurang memadai. (2) Adanya peraturan dari pimpinan rumah sakit untuk menggunakan komputer. Karyawan rumah sakit dengan umur 20-35 tahun diwajibkan menggunakan komputer sesuai dengan pekerjaannya. (3) Ruang server sudah berpindah sampai 3 kali. Ruang server saat ini masih digabung dengan kantor bagian SIM dan gudang komponen komputer. (4) Aplikasi rusak atau komponen rusak terjadi rata-rata 1-2 kali dalam sehari. (5) Rumah sakit RAA Soewondo baru saja berubah menjadi Badan Layanan Umum Daerah (BLUD). Penyusunan anggaran dana dan pengangkatan pegawai menjadi lebih fleksibel sejak menjadi BLUD. (6) SIRS lama tidak memadai dalam hal memenuhi persyaratan BLUD yaitu perubahan sistem remunerasi berbasis kinerja karyawan, bukan berbasis pangkat atau lama bekerja di rumah sakit. (7) Penganggaran dana untuk pembuatan dan implemetasi SIRS baru sudah dimasukkan kedalam RAPBD kabupaten Pati 2010. (8) Pemimpin rumah sakit mengharapkan SIRS yang baru nanti dapat membuat data menjadi lebih absah sehingga tidak terjadi bias dalam mengambil kebijakan. (9) Divisi SIM sudah menjadi bagian yang penting dalam proses rumah sakit melayani pasiennya. Gangguan pada SIRS dapat mengganggu proses pelayanan rumah sakit dan dapat mengganggu kenyamanan pasien. (10) Tidak ada reward dan punishment dalam keterlibatan karyawan dalam implementasi SIRS baru. (11) Belum adanya sosialisasi tentang perubahan SIRS baru di lingkungan rumah sakit.

Hasil Observasi. Observasi dilakukan pada lingkungan rumah sakit RAA Soewondo. Hasil observasi terdiri dari 12 poin. (1) Tidak ada sosialisasi perubahan SIRS dalam lingkungan rumah sakit. Hal ini ditunjukkan dengan tidak tahunya karyawan yang diberikan kuesioner tentang rencana perubahan SIRS. (2) Ruang server memiliki pendingin ruangan dan UPS untuk cadangan jika listrik mati. (3) Jumlah pegawai SIM adalah lima orang dan hanya ada pada jam kerja (07.00-14.00). Jika terjadi kerusakan pada malam hari, maka karyawan yang 
mengetahuinya akan menghubungi kepala SIM. Perbaikan baru akan dikerjakan pada pagi harinya. Karyawan SIM akan datang lebih awal untuk mengatasi kerusakan. (4) Jumlah kunjungan pasien rawat jalan cukup tinggi, ditunjukkan dengan banyaknya antrian pada bagian pendaftaran pasien dan pelayanan oleh dokter. (5) Pengguna SIRS sudah terbiasa dengan aplikasi yang berjalan saat ini. Mereka dengan mudah dapat segera mengoperasikan SIRS jika ada data yang perlu di-input atau diubah. (6) Terdapat pengumuman standar operasional prosedur (SOP) yang ditempel di depan monitor tiap client. SOP tersebut memberitahukan langkah yang harus dilakukan jika pengguna menemui masalah pada SIRS. Hal ini untuk mempermudah pengguna jika ada masalah dengan SIRS dan mencegah pengguna merusak SIRS lebih lanjut. (7) Bagian pelayanan laboratorium harus memberikan pelatihan sendiri kepada staff-nya untuk mengoperasikan peralatan laboratorium. Peralatan laboratorium mengharuskan mereka memakai komputer. (8) Laboratorium tidak memiliki Laboratory Information System sehingga data analisis yang dihasilkan dari alat laboratorium yang memakai komputer harus dimasukkan ulang ke dalam SIRS. (9) Penyediaan pelatihan tidak diberikan oleh bagian SIM jika pengadaan perangkat lunak (software) tidak menjadi tanggung jawab mereka. (10) Komputer yang dipakai oleh client memiliki spesifikasi Pentium 3 atau Pentium 4 tanpa hard disk. (11) Bagian Keperawatan dan Laboratorium bekerja 24 jam dan dibagi dalam shift. (12) Secara umum pengguna SIRS patuh pada peraturan yang ditetapkan rumah sakit dan akan melakukan apa yang ditetapkan tanpa banyak upaya untuk meyakinkannya.

Proses analisis dilakukan terhadap tiga faktor, yakni analisis faktor resistensi, analisis lingkungan Rumah Sakit, dan analisis tindakan perubahan. Terakhir akan dilakukan pengelompokkan tindakan perubahan ke dalam strategi perubahan.

Pertama, Analisis Faktor Resistensi. Hanya sebagian kecil yang menolak pergantian SIRS yaitu sebesar $16 \%$ (12 responden) dari total responden. Mereka berargumen bahwa SIRS yang ada saat ini sudah cukup memadai dan hanya perlu disempurnakan saja. Dari $16 \%$ responden yang menolak, dua diantaranya memiliki jabatan Kepala Instansi Penunjang rumah sakit. Observasi dilakukan pada rumah sakit khususnya pada unit pelayanan dan unit administrasi yang menggunakan komputer sebagai bagian dari pekerjaan mereka sehari-hari. Dari observasi terlihat bahwa pengguna SIRS sudah terbiasa dengan kondisi operasional saat ini. Mereka dapat dengan cepat melakukan input dan merubah data. Pelatihan karyawan yang diberikan oleh bagian SIM untuk mempelajari SIRS sudah tidak ada lagi. Proses pembelajaran operasional SIRS diberikan oleh atasan kepada staff-nya dalam rangka untuk memercepat proses pekerjaan di unit tersebut. Bila terjadi perubahan SIRS maka atasan unit layananlah yang harus memberikan pelatihan lagi kepada staff-nya. Mereka menganggap pelatihan yang diberikan oleh bagian SIM masih bersifat umum dan kurang mendalam di bagian mereka. Hal inilah yang menyebabkan munculnya resistensi penerapan SIRS baru.

Solusi harus diberikan untuk mengurangi resistensi implementasi SIRS. Resistensi ini walaupun kecil namun tetap harus diperhatikan. Solusi yang dapat dilakukan adalah meningkatkan kegiatan sosialiasi kepada karyawan rumah sakit. Kemudian memberikan pelatihan operasional SIRS baru yang sesuai dengan unit layanan.

Solusi ini dapat dimasukkan ke dalam metode manajemen Anderson dan Anderson untuk lebih memertegas dan memberikan masukan yang sesuai dengan resistensi yang ada di rumah sakit.

Kedua, Analisis Lingkungan Rumah Sakit. Terdapat delapan kekuatan yang dimiliki rumah sakit. (1) Adanya peran atasan dalam penyampaian informasi kegiatan. (2) Kemauan karyawan yang tinggi untuk empelajari aplikasi baru sesuai pekerjaannya. (3) Tingkat kepatuhan karyawan yang tinggi akan proses perubahan SIRS. (4) Kesediaan karyawan untuk dijadikan tempat bertanya bila teman menemui kesulitan. (5) Waktu kegiatan sosialisasi dan implementasi yang cukup. (6) Adanya standar operasional prosedur (SOP) yang baik dan mudah di tiap unit layanan yang menggunakan SIRS. (7) Adanya review kegiatan oleh atasan. (8) Peningkatan kinerja tiap unit layanan rumah sakit dengan adanya SIRS.

Peneliti juga menganalisis kelemahan yang dimiliki rumah sakit. (1) Frekuensi pertemuan yang terlalu jarang (1 bulan sekali). (2) Jumlah staf TI hanya berjumlah 5 orang dan bertugas hanya pada jam kerja kantor. (3) Kurang samanya visi dan misi terhadap keperluan SIRS baru. (4) Tidak adanya lagi pelatihan TI untuk karyawan baru. (5) SIRS sekarang tidak dapat di-upgrade kinerjanya lagi. (6) Adanya aplikasi dan perawatan SI yang bukan di bawah tanggung jawab bagian SIM. (7) SIRS sekarang memiliki kekurangan dalam pilihan menu dan tidak dapat menampilkan grafik atau chart. (8) Belum tersedia sistem remunerasi karyawan berbasis kinerja. (9) Aplikasi di beberapa unit layanan tidak terintegrasi dengan SIRS. (10) Penggunaan SIRS lama. 
Terdapat lima peluang yang dimiliki rumah sakit. (1) Kunjungan pasien yang tinggi. (2) Posisi rumah sakit yang terdepan dalam pelayanan medis di Kabupten Pati. (3) Penguasaan SI merupakan bagian dari persaingan. (4) Meningkatnya tuntutan masyarakat akan pelayanan rumah sakit yang bermutu. (5) Adanya kerja sama dengan pihak ketiga seperti ASKES, Bank Jateng, dan Jamkesmas.

Terakhir, peneliti juga menganalisis ancaman yang dimiliki rumah sakit. (1) Vendor $\mathrm{SI} / \mathrm{TI}$ bisa masuk ke rumah sakit tanpa melewati bagian SIM tetapi langsung berhubungan dengan unit layanan. (2) Dana anggaran perubahan dan implementasi SIRS baru yang tidak begitu besar dibanding rumah sakit pemerintah lainnya di Jawa Tengah. (3) Banyaknya rumah sakit swasta yang berdiri di Kabupaten Pati

Ketiga, Tindakan Perubahan Berdasarkan Matriks SWOT (tabel I). Matriks SWOT dilakukan untuk membuat tindakan perubahan yang diperlukan agar implementasi SIRS baru berjalan lancar. Tindakan perubahan didapat dari keadaan lingkungan internal dan eksternal di rumah sakit RAA Soewondo.

TABEL I

MATRIKS TINDAKAN PERUBAHAN BERDASARKAN MATRIKS SWOT

\begin{tabular}{lll}
\hline \hline & Strengths & Weaknesses \\
\hline Opportunities & Opportunities- & Opportunities- \\
& Strenghts & Weaknesses \\
Threats & Threats-Strenghts & Threats-Weaknesses \\
\hline \hline
\end{tabular}

Terdapat delapan tindakan perubahan berdasarkan kombinasi Opportunities-Strenghts matriks SWOT. (1) Memertahankan dukungan atasan dan manajemen untuk proses perubahan SIRS lama ini. (2) Melakukan sosialisasi kegiatan perubahan SIRS baru ke seluruh level organisasi. (3) Evaluasi berkala pelaksanaan SIRS baru. (4) Pelatihan SIRS baru secara bertahap yang sesuai pada bagian unit layanan kritis dan memiliki dampak yang besar terhadap perubahan ini. (5) Memberdayakan peran atasan untuk menyukseskan implementasi SIRS baru. (6) Melakukan review kegiatan implementasi secara berkala. (7) Lakukan analisis dampak penerapan implementasi terhadap masing-masing unit layanan dan pasien rumah sakit. (8) Pembuatan peraturan atau kebijakan dalam hal penggunaan SIRS baru.

Terdapat delapan tindakan perubahan berdasarkan kombinasi OpportunitiesWeaknesses. (1) Meningkatkan jumlah tenaga TI dan kualitas SDM TI. (2) Melakukan pertemuan tingkat manajemen untuk melakukan persamaan visi dan tujuan dari perubahan SIRS ini. (3) Meningkatkan frekuensi pertemuan di tiap unit untuk menyukseskan implementasi SIRS. (4) Perluasan tanggung jawab divisi SIM untuk mengatur SI/TI rumah sakit. (5) Pembuatan aturan yang jelas tentang penggunaan SIRS. 6) Memasukkan kemampuan pengetahuan operasional aplikasi SI dalam penilaian kinerja karyawan. (7) Lakukan survei dan wawancara untuk mendapatkan informasi perubahan apa saja yang diinginkan pengguna terhadap SIRS baru. (8) Memilih metode penggantian SIRS yang tepat tanpa mengganggu pelayanan pasien dan proses bisnis lainnya.

Terdapat sepuluh tindakan perubahan berdasarkan kombinasi Threats-Strengths. (1) Penutupan akses dan pemanfaatan SIRS lama. (2) Mencari vendor yang memiliki badan hukum yang baik. (3) Memonitor kinerja vendor dalam pembuatan atau implementasi SIRS baru. (4) Menjaga agar proses perubahan penggantian SIRS lama berjalan tepat waktu. (5) Menggunakan bahasa aplikasi pemrograman yang didukung perusahaan besar, stabil, teruji, dan berprospek. (6) Menggunakan teknologi informasi open source untuk pembuatan SIRS yang terbukti handal dan teruji. (7) Melakukan testing SIRS baru sebelum dipakai di seluruh unit layanan. (8) Penyempurnaan SOP sesuai dengan SIRS baru. (9) Interkoneksi aplikasi yang terpisah dengan SIRS baru. (10) Studi banding SIRS dengan rumah sakit lain.

Terdapat enam tindakan perubahan berdasarkan Threats-Weaknesses. (1) Memberikan penghargaan kepada karyawan yang baik dalam kinerja dan mendukung suksesnya implementasi SIRS. (2) Mengganti SIRS FOXPRO lama. (3) Menghentikan dukungan terhadap SIRS lama. (4) Pembuatan SOP SIRS yang mudah dimengerti oleh penggunanya. (5) Pembuatan sistem remunerasi karyawan berbasis kinerja. (6) Informasikan kepada seluruh karyawan bahwa implementasi SIRS baru berhasil.

Pengelompokkan Tindakan Perubahan ke Dalam Strategi Perubahan. Tindakan perubahan yang telah dihasilkan melalui analisis matriks SWOT, selanjutnya akan dikelompokkan menjadi model manajemen perubahan. Model manajemen perubahan dibuat berdasarkan Anderson and Anderson Nine Phase Change Process Model. Berikut hasil pengelompokan strategi perubahan menurut Anderson and Anderson Nine Phase Change Process Model.

Tahap pertama, prepare to lead the change. Pada tahap ini, dilakukan kegiatan: memertahankan dukungan atasan dan manajemen untuk proses perubahan SIRS lama, memberdayakan peran atasan untuk menyukseskan implementasi SIRS baru, perluasan 
tanggung jawab divisi SIM untuk mengatur SI/TI rumah sakit, peningkatan jumlah tenaga TI dan kualitas SDM TI. Tahap kedua, create organizational vision, commitment. Pada tahap ini, dilakukan kegiatan: melakukan sosialisasi kegiatan perubahan SIRS baru ke seluruh level organisasi, melakukan pertemuan level manajemen untuk melakukan persamaan visi dan tujuan dari perubahan SIRS ini. Tahap ketiga, assess the situation to determine design. Pada tahap ini, dilakukan kegiatan: studi banding SIRS dengan rumah sakit lain, melakukan survei dan wawancara untuk mendapatkan informasi perubahan apa saja yang diinginkan pengguna terhadap SIRS baru. Tahap keempat, design the desire state. Pada tahap ini, dilakukan kegitan: menggunakan bahasa aplikasi pemrograman yang didukung perusahaan besar, stabil, teruji, dan berprospek, menggunakan teknologi informasi open source untuk pembuatan SIRS yang terbukti handal dan teruji, interkoneksi aplikasi yang terpisah dengan dari SIRS baru, pembuatan sistem remunerasi karyawan berbasis kinerja. Tahap kelima, analyze the impact. Pada tahap ini, dilakukan kegiatan: melakukan testing SIRS baru sebelum dipakai di seluruh unit layanan, memilih metode penggantian SIRS yang tepat tanpa menggangu pelayanan pasien dan proses bisnis lainnya, melakukan analisis dampak penerapan implementasi terhadap masing-masing unit layanan dan pasien rumah sakit. Tahap keenam, plan and organize for implementation. Pada tahap ini, dilakukan kegiatan: pelatihan SIRS baru secara bertahap yang sesuai pada bagian unit layanan kritis dan memiliki dampak yang besar terhadap perubahan ini, meningkatkan frekuensi pertemuan di tiap unit untuk menyukseskan implementasi SIRS, pembuatan aturan yang jelas tentang penggunaan SIRS, mencari vendor yang memiliki badan hukum yang baik, menjaga agar proses perubahan penggantian SIRS lama berjalan tepat waktu. Tahap ketujuh, implement the change. Pada tahap ini, dilakukan kegiatan: mengganti SIRS lama, me-monitor kinerja vendor dalam pembuatan atau implementasi SIRS baru. Tahap kedelapan, celebrate and integrate the new state. Pada tahap ini, dilakukan kegiatan: memasukkan kemampuan pengetahuan operasional aplikasi SI dalam penilaian kinerja karyawan, memberikan penghargaan kepada karyawan yang baik dalam kinerja dan mendukung suksesnya implementasi SIRS, menghentikan dukungan terhadap SIRS lama, penutupan akses dan pemanfaatan SIRS lama, informasikan kepada seluruh karyawan bahwa implementasi SIRS baru berhasil. Tahap kesembilan, learn and course correct. Pada tahap ini, dilakukan kegiatan: melakukan review kegiatan implementasi secara berkala, evaluasi berkala pelaksanaan SIRS baru, pembuatan SOP SIRS yang mudah dimengerti oleh penggunanya, pembuatan peraturan atau kebijakan dalam hal penggunaan SIRS baru.

\section{Kesimpulan}

Terdapat kesimpulan-kesimpulan dari penelitian ini, yakni: (1) Terdapat resistensi individu yang relatif kecil (16\%) terhadap implementasi SIRS baru, (2) Tindakan perubahan SIRS yang baru, dicari menggunakan kombinasi matriks SWOT, (3) Model yang digunakan untuk mengelompokkan strategi perubahan dari tindakan perubahan adalah Anderson and Anderson Nine Step Change Process Model, (4) Manajemen perubahan digunakan dalam proses implementasi SIRS agar proses perubahan berjalan sesuai dengan tujuan perubahan, (5) Proses perubahan SIRS pada rumah sakit RAA Soewondo seharusnya mudah dilakukan karena sebagian besar responden mendukung adanya perubahan pada SIRS yang ada saat ini.

Saran-saran yang dapat diberikan untuk memercepat proses implementasi SIRS baru adalah penelitian lanjutan dapat dilakukan untuk melihat penerapan atau tingkat keberhasilan proses implementasi SIRS dalam kaitannya dengan penerapan strategi manajemen perubahan di rumah sakit. Selain itu pembuatan strategi dan langkah dalam proyek TI khususnya dalam proyek implementasi SIRS dengan vendor dapat dibuat untuk membantu pihak manajemen dalam memperlancar pelaksanaan dan pengawasan proyek. Pembuatan strategi ini dapat dijadikan bahan untuk penelitian selanjutnya di rumah sakit RAA Soewondo. 


\section{Referensi}

[1] M. Levinson, When Failure is Not Option, Framingham, 2006.

[2] T.D. Jick \& M.A. Peiperl, Managing Change: Cases and Concepts, McGraw-Hill Irwin, New York, 2002.

[3] E.A. Mutholib, "Strategi Manajemen Perubahan Untuk Mempercepat Implementasi Sistem Informasi Rumah Sakit: Studi Kasus Rumah Sakit Medistra," $\mathrm{Ph} . \mathrm{D}$ Thesis, Magister of Information Technology, Universitas Indonesia, Indonesia, 2007.

[4] E.E. Tozer, Strategic IS/IT planning, Professional ed., Betterworth-Heinemann, Boston, 1996.
[5] S.P. Robbin, Organizational Behavior, 10th ed., Prentice Hall, Upper Saddle River, 2003.

[6] B.P. Lientz \& K.P. Rea, Breakthrough IT Change management, Elseiver Butterwoth Heinemann, USA, 2004.

[7] D. Anderson \& L.A. Anderson, Beyond Change Management: Advanced Strategies for Today's transformational Leaders, Jossey-Bass, USA, 2001.

[8] P. Phookun, Audit of IT Systems Development, http://www.asosai.org/journal2002/articles_1 .htm, 2002, retrieved December 21, 2009. 